\title{
Endodrainage, Tumor Photocoagulation, and Silicone Oil Tamponade for Primary Exudative Retinal Detachment due to Choroidal Melanoma Persisting after Proton Beam Therapy
}

\author{
Ira Seibel $^{a}$ Dino Cordini ${ }^{a, b} \quad$ Gregor Willerding ${ }^{a, c}$ Aline Isabel Riechardt ${ }^{a}$ \\ Antonia Maria Joussen ${ }^{a}$ \\ ${ }^{a}$ Department of Ophthalmology, Charité University Medicine Berlin, ${ }^{b}$ BerlinProtonen, \\ Helmholtz-Zentrum Berlin für Materialien und Energie, and ${ }^{\mathrm{C}}$ Klinik für Augenheilkunde an \\ den DRK Kliniken Berlin/Westend, Berlin, Germany
}

\author{
Key Words \\ Choroidal melanoma - Exudative retinal detachment - Proton beam therapy - Endodrainage
}

\begin{abstract}
Background: Choroidal melanoma is frequently accompanied by an exudative retinal detachment that can persist after proton beam therapy. This study investigates whether vitrectomy without tumor resection improves the clinical outcome. Methods: This is a retrospective interventional case series. Twenty patients with choroidal melanoma with exudative retinal detachment involving the macula were treated by vitrectomy, endodrainage, photocoagulation, and silicone oil tamponade after proton beam therapy. Results: The mean follow-up was 38.4 months (median 21.5, range 12.0-122.0). The mean time between proton beam therapy and surgery was 4.5 months (range 0.1-9.2). Reattachment was achieved in $95 \%$ of the patients after one vitrectomy. One patient was lost to follow-up because enucleation was performed after 45.9 months due to a secondary glaucoma. Mean visual acuity decreased from 1.1 to 1.8 logMAR before vitrectomy and after 4 years, respectively. No patient showed local tumor recurrence. Metastatic disease was present in 1 patient after 15.2 months, and this patient died after 19.2 months. Conclusion: Vitrectomy is indicated after therapeutic proton beam irradiation in patients who present with persisting exudative retinal detachment involving the macula and high local or systemic risk factors for hemorrhagic complications, thus excluding endoresection.


Ocular Oncology

and Pathology

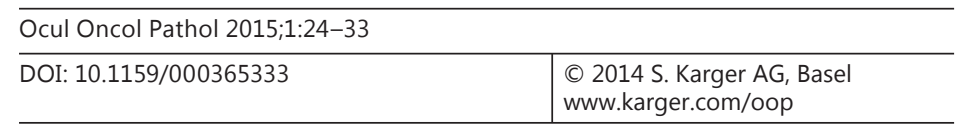

Seibel et al.: How to Manage Retinal Detachment Persisting after Proton Beam Therapy

\section{Introduction}

Choroidal melanoma is the most frequent primary intraocular malignancy in adults. One part of ocular oncology is local and systemic tumor control. The enucleation of the eye shows equal metastatic mortality rates; therefore, preservation of the organ - even for large choroidal melanoma - should be the aim. Central location and size of the tumor are limiting conditions for the visual outcome in the eye-preserving radiation treatment. Choroidal melanomas with localization in the periphery are frequently accompanied by exudative retinal detachment limiting the vision. Tumor size is a strong predictor of exudative retinal detachment [1]. Exudative detachment often exacerbates after proton or gamma-knife irradiation, especially in large tumors [2]. Persistence of exudation after tumor irradiation is not necessarily a sign of tumor recurrence or activity. It is attributable to persistent tumorous vascular mediated breakdown of the blood-retinal barrier.

Tumor exudation is a risk factor for vision loss, especially when the foveal region is involved [3, 4]. Histochemical studies have indicated significant loss of photoreceptors following retinal detachment due to apoptotic and necrotic cellular death mechanisms [5-9]. This may explain the correlations between tumor exudation and its duration as well as irreversible deterioration of vision. Functional outcomes depend inversely on the lag duration between retinal detachment and reattachment. Furthermore, exudative retinal detachment is a risk factor for neovascular glaucoma possibly leading to enucleation with no influence on survival rates $[2,4,10-13]$.

Conservative treatment options are limited. Spontaneous regression of the exudation may appear within up to 1 year $[14,15]$. Resolution can be accelerated with the application of systemic or intravitreal steroids [16]. Gibran and Kapoor [15] proved in vivo that visual outcome can be restored by a contemporary reattachment. They performed a pars plana vitrectomy with endodrainage and silicone oil tamponade at the time of radiation therapy.

Our study reports the outcome of vitrectomy, endodrainage, photocoagulation, and silicone oil tamponade in patients with persistent exudative retinal detachment after proton beam irradiation for choroidal melanoma.

\section{Patients and Methods}

This retrospective study included patients with a primary exudative retinal detachment involving the fovea due to choroidal melanoma at the time of diagnosis that persisted after proton beam therapy. Also included were patients whose comorbidities (hypertension, nonreplaceable anticoagulation) or tumor characteristics (e.g. ciliary body involvement, $>18 \mathrm{~mm}$ largest tumor diameter) excluded the possibility of surgical tumor resection due to a high risk of perioperative hemorrhage. All patients had a minimum follow-up of 12 months. Patients treated with vitrectomy for any other reason than the exudative retinal detachment (e.g. vitreous hemorrhage, rhegmatogenous or tractional retinal detachment, or any prior or further treatment between the time of diagnosis and vitrectomy) were excluded from the study. All patients gave their informed consent. The study protocol was approved by the Committee on Human Research of the Charite University Medicine Berlin.

All patients were treated between 2003 and 2011 at the Department of Ophthalmology, Charité University Medicine Berlin. Surgical treatment was performed after application of proton beam therapy at the Helmholtz-Zentrum Berlin. The diagnosis of choroidal melanoma was made by using slit-lamp examination, ophthalmoscopy as well as A- and B-scan sonography using standard techniques. The investigated endpoints of this study were the functional and anatomical outcome as well as local or systemic complications (cataract, radiation optic neuropathy, radiation retinopathy, neovascular glaucoma, tumor-related lipid exudation, enucleation rate, metastasis rate, and local recurrence). Visual acuity was measured as bestcorrected visual acuity before any vitrectomy and after year 1 , year 2, year 3, and year 4 . Additionally, we report on 5 further patients with ciliary body involvement. Due to different anatomic features, such as ciliary body involvement, they have been observed separately and are reported in tables 1 and 2 . 
Table 1. Anatomical and treatment characteristics regarding tumor type (choroidal melanoma and choroidal ciliary body melanoma), largest tumor diameter, tumor height, irradiation doses (to fovea and optic disc), and tumor localization

\begin{tabular}{|c|c|c|c|c|c|c|}
\hline $\begin{array}{l}\mathrm{Pa}- \\
\text { tient }\end{array}$ & $\begin{array}{l}\text { Peripheral/ } \\
\text { central }\end{array}$ & Tumor localization $^{\mathrm{a}}$ & $\begin{array}{l}\text { Ciliary body } \\
\text { involvement }\end{array}$ & $\begin{array}{l}\text { LTD, } \\
\mathrm{mm}\end{array}$ & $\begin{array}{l}\text { Initial tumor } \\
\text { height, mm }\end{array}$ & $\begin{array}{l}\text { Tumor height } \\
\text { at follow-up, mm }\end{array}$ \\
\hline 1 & peripheral & distance to fovea and optic disc & no & 16.5 & 10 & 3.2 \\
\hline 2 & peripheral & distance to fovea and optic disc & no & 11.4 & 6.7 & 2.5 \\
\hline 3 & peripheral & distance to fovea and optic disc & no & 16.6 & 4.4 & 3.4 \\
\hline 4 & central & distance to fovea, 1.1-mm distance to optic disc & no & 18.2 & 5.7 & 3.9 \\
\hline 5 & central & subfoveal, circumpapillary & no & 7.7 & 5.1 & silicone oil \\
\hline 6 & central & juxtafoveal, distance to optic disc & no & 16.8 & 5.7 & 1.2 \\
\hline 7 & central & distance to fovea, juxtapapillary & no & 10.2 & 3.8 & 1.6 \\
\hline 8 & central & juxtapapillary, distance to optic disc & no & 14.3 & 7.6 & silicone oil \\
\hline 9 & central & distance to fovea, juxtapapillary & no & 15.9 & 8.1 & silicone oil \\
\hline 10 & central & juxtafoveal, distance to optic disc & no & 14.4 & 6.2 & 4.8 \\
\hline 11 & central & subfoveal, juxtapapillary & no & 10.2 & 4 & 3.1 \\
\hline 12 & central & juxtafoveal, distance to optic disc & no & 14.2 & 7.3 & silicone oil \\
\hline 13 & central & distance to fovea, juxtapapillary & no & 14.5 & 5.8 & 2.5 \\
\hline 14 & central & juxtafoveal, circumpapillary & no & 14.2 & 5.7 & 1.9 \\
\hline 15 & central & 1.7-mm distance to fovea, juxtapapillary & no & 13.6 & 6.8 & silicone oil \\
\hline 16 & central & 1.4-mm distance to fovea, circumpapillary & no & 14.7 & 7.3 & silicone oil \\
\hline 17 & central & subfoveal, $1.5-\mathrm{mm}$ distance to optic disc & no & 12.8 & 4.9 & silicone oil \\
\hline 18 & central & 0.5-mm distance to fovea, circumpapillary & no & 13.3 & 6.1 & 2.6 \\
\hline 19 & central & 0.5-mm distance to fovea, circumpapillary & no & 15 & 7.1 & 4.1 \\
\hline 20 & central & distance to fovea, $1.2-\mathrm{mm}$ distance to optic disc & no & 18.5 & 5.5 & silicone oil \\
\hline 21 & peripheral & distance to fovea and optic disc & yes & 22 & 7 & silicone oil \\
\hline 22 & peripheral & distance to fovea and optic disc & yes & 19.1 & 8.2 & silicone oil \\
\hline 23 & peripheral & distance to fovea and optic disc & yes & 18.3 & 8.7 & 4.1 \\
\hline 24 & peripheral & distance to fovea and optic disc & yes & 20 & 10 & 5.7 \\
\hline \multirow[t]{2}{*}{25} & central & 2-mm distance to fovea, $1.1-\mathrm{mm}$ distance to & & & & \\
\hline & & optic disc & yes & 20 & 9.8 & silicone oil \\
\hline
\end{tabular}

\footnotetext{
${ }^{\text {a }}$ Distance $>2.5 \mathrm{~mm}$. LTD $=$ Largest tumor diameter.
}

\section{Surgery}

After irradiation, a standard 20-gauge three-port vitrectomy with posterior vitreous detachment was performed. Retinal reattachment was achieved using perfluorocarbon heavy liquids. To drain the subretinal fluid, a small peripheral retinotomy was generated using the vitreous cutter. Afterwards, endolaser photocoagulation $(532 \mathrm{~nm})$ was applied confluently to the tumor surface as well as to the retinotomy borders (Iridex Corp., Canada). All eyes received a silicone oil 5000 cSt tamponade. No systemic or local steroids exceeding a 2-hourly application of $1 \mathrm{mg} / \mathrm{ml}$ dexamethasone solution were administered during the postoperative period. Silicone oil removal was performed using a further three-port vitrectomy when exudation had completely disappeared and visual outcome was expected to remain within a useful range (e.g. above counting fingers). Silicone oil removal was further performed when complications of silicone oil tamponade (e.g. emulsification and secondary silicone-related glaucoma) were present.

\section{Statistics}

Statistical analysis was performed with SPSS 20.0. A Mann-Whitney U test, Fisher's exact test, and factorial ANOVA were used to assess differences between subgroups. Interrelationships between variables were assessed by calculating correlation coefficients according to Spearman/PeaMAR. In relation to the MARAN (adjusted meter vision) protocol, light perception was added as $2.1 \operatorname{logMAR}$, hand motion as 2.0 $\log$ MAR, and counting fingers as $1.9 \log$ MAR [17]. 
Ocular Oncology

and Pathology

Table 2. Best-corrected visual acuity in logMAR before surgery and in years 1-4 of follow-up based on tumor type (choroidal melanoma and choroidal ciliary body melanoma)

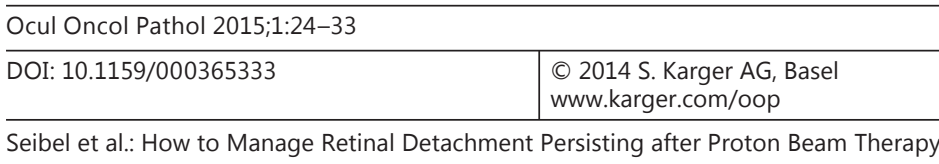

\begin{tabular}{rllllll}
\hline $\begin{array}{l}\text { Pa- } \\
\text { tient }\end{array}$ & $\begin{array}{l}\text { Ciliary body } \\
\text { involvement }\end{array}$ & $\begin{array}{l}\text { BCVA before } \\
\text { vitrectomy }\end{array}$ & $\begin{array}{l}\text { BCVA } \\
\text { year 1 }\end{array}$ & $\begin{array}{l}\text { BCVA } \\
\text { year 2 }\end{array}$ & $\begin{array}{l}\text { BCVA } \\
\text { year 3 }\end{array}$ & $\begin{array}{l}\text { BCVA } \\
\text { year 4 }\end{array}$ \\
\hline 1 & no & 1 & 1 & & & \\
2 & no & 0.7 & 0.2 & 0.4 & & \\
3 & no & 1 & 1 & 1 & & \\
4 & no & 2 & 2 & 1 & & \\
5 & no & 1.4 & 1.5 & & & \\
\hline 6 & no & 2 & 1.3 & 1.4 & 1.7 & \\
7 & no & 0.5 & 0.5 & & & \\
8 & no & 1 & 1 & & & \\
9 & no & 1.3 & 2 & & & \\
10 & no & 0.6 & 0.7 & & & \\
\hline 11 & no & 1.5 & 2 & 1.4 & & \\
12 & no & 2 & 2 & & & \\
13 & no & 0.4 & 0.5 & 1.5 & 0.7 & 1 \\
14 & no & 1.2 & 1.2 & 1.5 & 2 & 2 \\
15 & no & 1 & 0.2 & 1.8 & & \\
\hline 16 & no & 0.7 & 0.7 & & & \\
17 & no & 2 & 1.3 & 1.3 & 2 & 2 \\
18 & no & 1 & 1 & 1.3 & 1.4 & 1.3 \\
19 & no & 1 & 1.3 & 2 & 2 & 2 \\
20 & no & 1.3 & 2 & 2.1 & 2.2 & 2.2 \\
\hline 21 & yes & 0.1 & 0.1 & & & \\
22 & yes & 0.9 & 1.5 & & & \\
23 & yes & 0.7 & 0.8 & & & \\
24 & yes & 0.3 & 0.7 & & & \\
25 & yes & 1 & 1.2 & 1.2 & & \\
\hline & & 1.3 & & & & \\
\hline
\end{tabular}

BCVA = Best-corrected visual acuity

\section{Results}

\section{Patients and Treatment}

The mean age at the time of vitrectomy was 55 years (range 26-84). Ten patients were female and 10 were male. The mean time to follow-up was 38.4 months (median 21.5, range 12.0-122.0).

\section{Anatomical Results}

Before surgery, the retinal detachment affected the fovea in all cases. We found partial detachment comprising one quadrant $(n=6)$, two quadrants $(n=9)$ or three quadrants $(n=$ 3 ). A total exudative retinal detachment was seen in 2 patients. The mean time between irradiation and surgery was 4.5 months (range 0.1-9.2). Vitrectomy and oil tamponade were successful in reattaching the retina in $100 \%(\mathrm{n}=20)$ of the cases without complications.

Silicone oil was removed after a mean time of 11.3 months (range 3.0-30.0) in 13 patients $(65.0 \%)$. The silicone tamponade was left in 7 patients $(35.0 \%)$ to avoid further surgery due to poor visual prognosis. However, no inferior retinal detachment was detected in any of the patients with remaining oil tamponade.

In 1 patient (5.0\%), retinal redetachment was observed 1.5 months after oil removal due to persisting exudation. There was no sign of proliferative vitreoretinopathy. Management in this case included revitrectomy with application of an encircling band, re-laser photocoagulation, and intraocular sulfurhexafluoride gas tamponade. The encircling band was used as adjuvant treatment in this complex situation to ensure that all vitreous has been removed for prevention of proliferative vitreoretinopathy. 
Ocular Oncology

and Pathology
Fig. 1. Best-corrected visual acuity in decimals after years 1-4 (only patients without ciliary body involvement were included). Median visual acuity before vitrectomy was 1.0 logMAR (mean 1.1, range 2.0-0.5) and stayed at that very poor level during the following 4 years (see table 2 for more information). After 1 year, the median visual acuity was $1.2 \log$ MAR (mean 1.1, range 2.0-0.2, $\mathrm{n}=20$ ) and did not change for more than 2 years (mean 1.4, range 2.0-0.4, $\mathrm{n}=12$ ). Three years after irradiation, visual acuity dropped to 2.0 logMAR (mean 1.7, range 2.2-0.7, $\mathrm{n}=$ 7) and remained stable thereafter (after 4 years: mean 1.8, range $2.2-1.0, n=6)$.

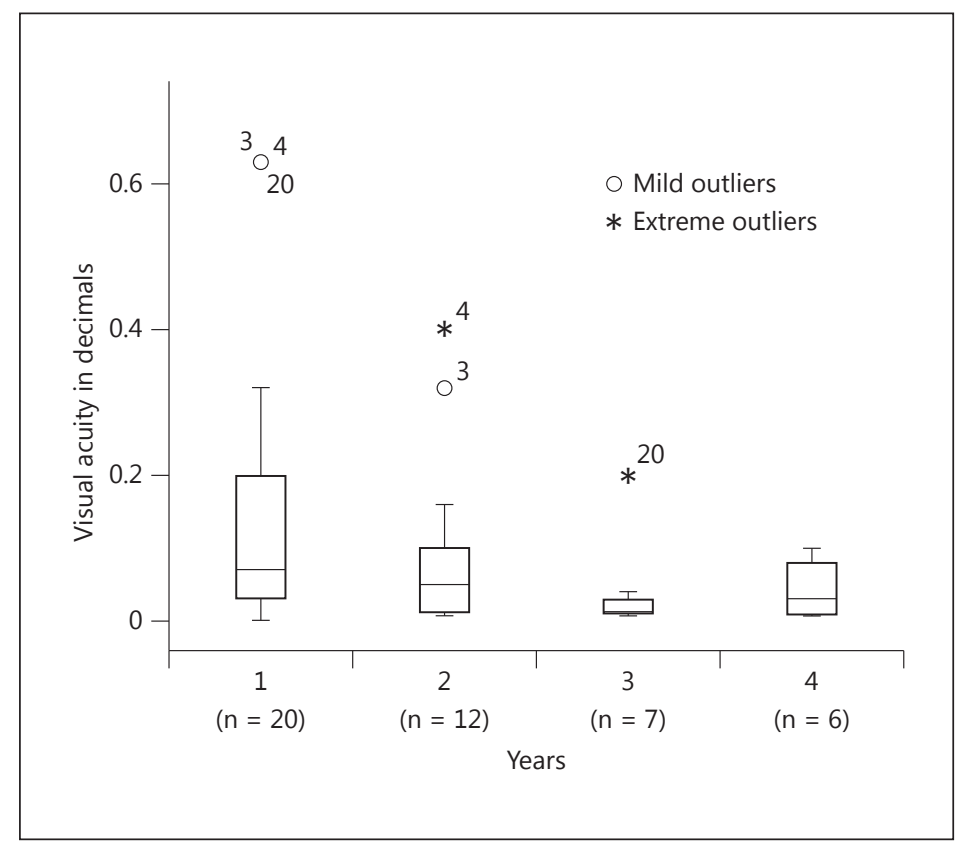

Mean tumor height prior to proton beam therapy was $6.2 \mathrm{~mm}$ (range 3.8-9.9) and 14.2 $\mathrm{mm}$ (range 7.7-18.5) in the largest basal diameter. The last examination showed that the mean tumor thickness decreased to $2.2 \mathrm{~mm}$ (range 1.2-4.8) after a mean follow-up of 38.4 months (median 21.5, range 12.0-122.0) ( $\mathrm{p}=0.002$ ). Although sonographic measurements were limited to patients who underwent oil removal $(n=13 ; 65.0 \%)$, tumor regression was seen in all patients ophthalmoscopically.

\section{Functional Results}

Before vitrectomy, the median visual acuity was 1.0 logMAR (mean 1.1, range 2.0-0.5) and stayed at that very poor level during the following 4 years (table 2). After 1 year, the median visual acuity was $1.2 \log$ MAR (mean 1.1 , range $2.0-0.2, \mathrm{n}=20$ ) and did not change for more than 2 years (mean 1.4, range $2.0-0.4, \mathrm{n}=12$ ). Three years after irradiation, visual acuity dropped to $2.0 \operatorname{logMAR}$ (mean 1.7 , range $2.2-0.7, \mathrm{n}=7$ ) and remained stable thereafter (after 4 years: mean 1.8, range $2.2-1.0, \mathrm{n}=6$ ) (fig. 1 ).

\section{Local Tumor Control and Complications}

None of the 20 patients showed local tumor recurrence. One patient (2.0\%) developed metastasis after 15.2 months and died after 19.2 months. Enucleation was performed in 1 patient (5.0\%) 45 months after vitrectomy because of neovascular glaucoma.

Complications observed during the follow-up included cataract development, lipid exudation, radiation retinopathy, radiation-induced optic neuropathy, and neovascular glaucoma. No patient presented with radiation-induced complications at the time of vitrectomy or earlier. Four patients $(20.0 \%)$ were pseudophakic at the time of diagnosis. Six patients $(30.0 \%)$ presented with cataracts at that time point. Most patients did not receive cataract surgery and silicone oil tamponade at the time of vitrectomy. Cataract surgery was carried out simultaneously with oil removal in 12 patients (60.0\%). One patient (5.0\%) was left aphakic. Two patients $(10.0 \%)$ did not develop a cataract until the final follow-up. One patient (2\%) developed massive lipid exudation after 15 months. 
Radiation retinopathy was found in 8 patients (40.0\%) after a mean interval of 7.1 months. Radiation-induced optic neuropathy occurred in 7 patients (35.0\%) after 9.2 months. Secondary glaucoma was detected in 5 cases $(20.0 \%)$ at an average of 9.3 months after proton beam therapy. There was no correlation found between visual outcome and development of complications.

\section{Subgroup Analysis of Choroidal Melanoma with Ciliary Body Involvement}

Patients presenting with ciliary body involvement were reported separately. Ciliary body involvement is a clinical feature that is independently associated with a higher risk of metastasis [18].

Mean follow-up in patients with ciliary body involvement was 16.4 months (median 15.2, range 13.0-21.8). Mean initial tumor height was $8.7 \mathrm{~mm}$ (range 7.0-10.0), and mean largest tumor diameter was $19.9 \mathrm{~mm}$ (range 18.3-22.0). Mean tumor height at the end of follow-up was $4.9 \mathrm{~mm}$ (range $4.1-5.7$; $\mathrm{p}=0.003$; table 1 ).

In the 5 patients with ciliary body involvement, retinal detachment extended to one quadrant in 1 patient, to two quadrants in 3 patients, and to three quadrants in 1 patient. The fovea was involved in all 5 patients. Surgery was performed after, on average, 4.9 months (range 0.3-10.2) following proton beam therapy.

Vitrectomy and oil tamponade were capable to reattach the retina in $100 \%(n=5)$ of the cases without any perioperative complication. In 2 patients, silicone oil was removed after 7 and 10 months, respectively. In the latter patient, 1 month after oil removal due to new exudative retinal detachment, a second vitrectomy, including encircling band and intraocular sulfur hexafluoride gas tamponade, was necessary to get the retina attached.

Best-corrected visual acuity in patients with ciliary body involvement before surgery and 1 year thereafter was $0.8 \log$ MAR (range 1.0-0.1) and 0.7 logMAR (range 1.0-0.1), respectively (table 2). At the time of diagnosis, 3 of 5 patients were pseudophakic and 2 presented with cataracts. Radiation retinopathy occurred in 2 patients after 3.7 and 13.1 months, respectively; the first patient (patient No. 25) experienced radiation-induced optic neuropathy after 3.7 months. None of the patients developed tumor-related exudation (yellowish exudates), metastasis or local recurrence, or secondary glaucoma (fig. 2).

\section{Discussion}

Our study demonstrates that vitrectomy with endodrainage, tumor endolaser coagulation, and silicone oil tamponade is a valid treatment option in patients with primary exudative retinal detachment due to choroidal or ciliary body melanoma. This treatment option becomes especially interesting when endoresection should be avoided in patients with a high risk of perioperative bleeding.

To our knowledge, there is only one study by Gibran and Kapoor [15], which describes a similar treatment in 6 patients after brachytherapy $(n=5)$ and proton beam therapy $(n=1)$. It was successfully performed in all 6 patients, except 1 case of retinal redetachment $(17 \%)$. Drawing a comparison with the present study is difficult because of different tumor characteristics. Gibran and Kapoor [15] reported only 1 patient with a large tumor (height of 11.2 $\mathrm{mm}$, basis of $16.5 \mathrm{~mm}$ ) who received proton therapy. Our study represents mainly patients with large tumors with an equal success rate for retinal reattachment. We reported 1 patient with redetachment due to persisting exudation. 
Ocular Oncology

and Pathology
Ocul Oncol Pathol 2015;1:24-33

DOI: 10.1159/000365333

www.karger.com/oop

Seibel et al.: How to Manage Retinal Detachment Persisting after Proton Beam Therapy
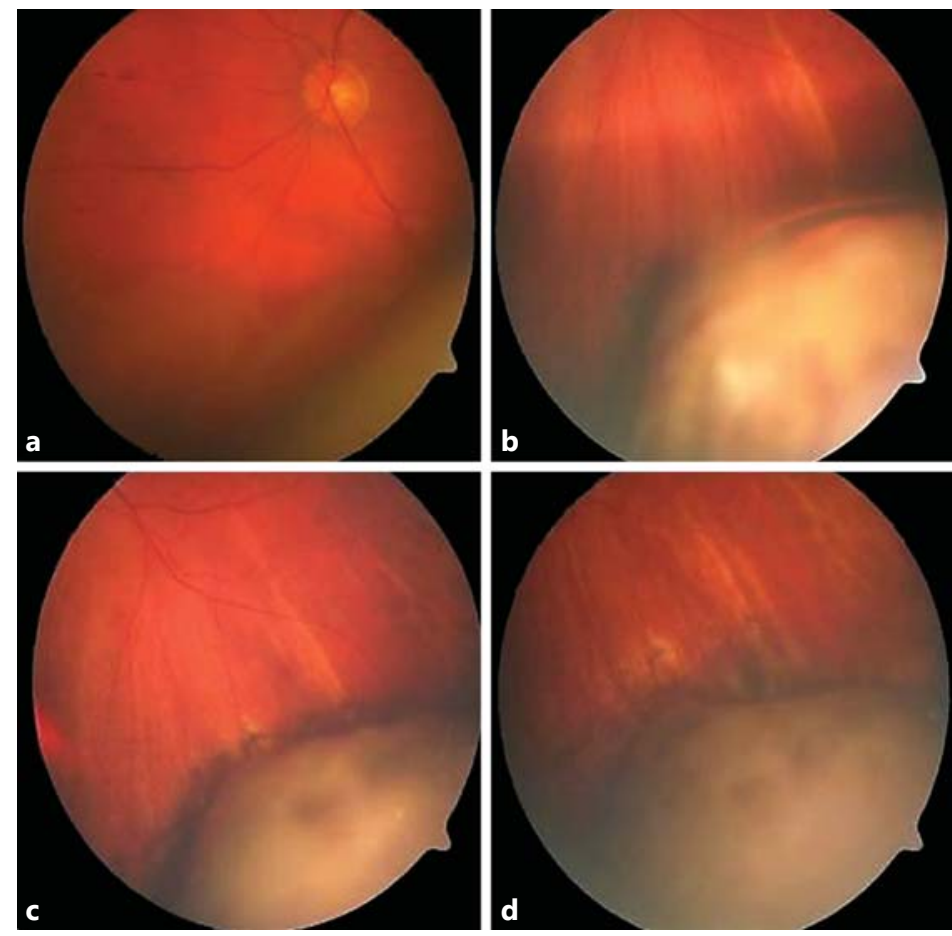

Fig. 2. a Patient presenting a choroidal melanoma with involvement of the ciliary body and exudative retinal detachment including the macula. Visual acuity was 0.2 $\operatorname{logMAR}$ and tumor thickness was $11 \mathrm{~mm}$. b Three months later, after surgical treatment including vitrectomy, endodrainage, endophotocoagulation, and silicone oil tamponade, the patient's visual acuity was $0.4 \log$ MAR. c One month after oil removal (oil was maintained for 3 months), his visual acuity was 0.2 $\operatorname{logMAR}$ and tumor thickness was $9 \mathrm{~mm}$. d Five months after oil removal, the patient's visual acuity was $0.1 \log$ MAR and tumor thickness was $6 \mathrm{~mm}$ (comparing the laser scars, further regression of tumor tissue is visible). The retina is attached, and no prominent inflammatory reaction is seen.

Experimental data suggest that in retinal detachment, permanent retinal degeneration might occur within weeks [5-9]. Gibran and Kapoor [15] proved in vivo that visual outcome can be restored by a contemporary reattachment. Thus, it seems reasonable to reattach the retina within a short period of time to maximize the visual-saving potential of this approach. Perhaps we would have had better functional outcomes if vitrectomy had been performed after a shorter period than we did (we had an irradiation/vitrectomy interval of 4.5 months).

Although nonsignificant in our study, there was a trend that shorter intervals between retinal detachment and silicone oil tamponade prevented visual loss. In our study, the shortest intervals between irradiation and vitrectomy were observed in 2 patients at 3 and 4 days after proton beam irradiation, respectively. Both patients experienced an improvement of visual acuity (from 1.0 to $0.3 \log$ MAR in the first patient and from 0.7 to $0.2 \log$ MAR in the second patient).

Besides the duration of retinal detachment, localization and size of the tumor are important parameters as irradiation therapy in proximity to sensitive structures necessarily causes vision loss. In the recent study, all but three tumors were classified as centrally located. Therefore, gain of function was limited by anatomic features.

We coagulated the retina overlaying the tumor with confluent laser during the vitrectomy and subsequent silicone oil tamponade. In our study, photocoagulation was not necessary for tumor control because prior irradiation sufficiently devitalized and inhibited the growth of the tumor cells. Instead, photocoagulation was applied with the intent to reduce the diffusion barrier of the retinal tissue overlaying the tumor by destruction and scarring of the retinal tissue.

After irradiation, tumor cells and vascular cells undergo apoptosis or necrosis resulting in exudation and inflammation [19]. Thus, after vitrectomy only, one would have expected more cases presenting with retinal redetachments as neither vitrectomy itself nor tamponade with silicone oil does influence the exudative activity of the tumor. In our study, photocoagu- 
lation of the tumor surface was performed using a frequency-doubled Nd/YAG laser. This laser coagulates the retina and superficial tumor layers and is not capable to achieve coagulative effects in tissue depths comparable to the probe used for transpupillary thermotherapy. There are reports demonstrating that laser tumor therapy $(810 \mathrm{~nm})$ in combination with proton therapy leads to resolution of exudative retinal detachments after 193 days compared to 263 days when only proton beam therapy was applied [20]. We assume that after photodestruction of retinal tissue overlying the tumor tissue, the exudative fluid may potentially diffuse into the vitreous cavity instead of subretinally. Limited amounts of persistent subretinal fluid are manageable and will be resorbed by the retinal pigment epithelium.

Furthermore, it is known that laser photocoagulation helps to prevent neovascular glaucoma [21]. In their study, Missotten et al. [22] found significantly elevated aqueous VEGF levels in eyes with uveal melanoma irrespective of the treatment compared with controls and eyes with a retinal detachment alone. The current literature shows overall 5-year neovascular glaucoma rates of approximately $11-31 \%$ in modern proton-treated uveal melanoma patients with neovascular glaucoma, and this typically occurs in the first 3 years after treatment [23-25]. In our study, the neovascular glaucoma rate was $20 \%$, which was not higher than reported in the literature for uveal melanoma in general. As mentioned above, exudative retinal detachment is a risk factor for neovascular glaucoma, which is the leading cause for enucleation [2, 4, 10-13]. Therefore, it would be interesting to perform VEGF measurements before and after vitrectomy to show that perhaps by reattachment of the retina, levels of VEGF are lowered to the same levels as in uveal melanoma in general.

By not removing the tumor, we were aware of an increased risk of retinal exudation and inflammation resulting in neovascular glaucoma called the 'toxic tumor syndrome'. As reported with increasing tumor mass, the irradiated tumor tissue may produce large amounts of cytokines leading to inflammation, VEGF expression, and subsequent barrier breakdown resulting in exudative retinal detachment and finally in neovascular glaucoma [26, 27]. In our study, the individual follow-up was still too short to detect differences in tumor-related exudations or neovascular glaucoma compared to patients who received endoresections at our department.

The additional use of intravitreal triamcinolone acetonide may minimize the need for postirradiation surgery as well as prevent exudative long-term damage. Pharmacological means to reduce exudative detachment encompass combinations anti-VEGF or steroid therapies $[16,28]$. Time until regression of exudation differed between $4.5( \pm 2.4)$ months with triamcinolone, $7.9( \pm 2.7)$ months with bevacizumab, and $11.2( \pm 3.5)$ months with observation. A complete retinal reattachment was found in 18 intravitreal triamcinolone acetonidetreated patients (56\%), 10 intravitreal bevacizumab-treated patients (31\%), and 7 observed patients $(22 \%)$. For this reason, we have recently started trying to reduce the retinal detachment by a combined treatment of triamcinolone during clip or cataract surgery, if necessary, before performing vitrectomy. Then, in case of persisting exudative retinal detachment, we decide on the further surgical approach, either vitrectomy including endoresection and silicone oil tamponade or vitrectomy including laser photocoagulation, endodrainage, and silicone oil tamponade.

In conclusion, following proton therapy of large choroidal tumors, additional therapy is required to maintain ocular integrity in a functional and anatomical way. While endoresection, especially in large tumors, was demonstrated to be the most promising way to retain the globe, vitrectomy with endodrainage can be a treatment option for those patients in whom an endoresection is not indicated [26, 27]. Accordingly, the study patients were selected for this treatment. While there is an effect on subretinal exudation, it remains unclear in which cases this treatment is sufficient to fully compensate for toxic tumor syndrome. Vitrectomy after proton beam therapy is a safe procedure, and vitrectomy facilitates tumor surveillance 
through reestablishing transparency of the visual axis. Furthermore, vitrectomy increases the chances of eye retention as it allows both panretinal photocoagulation to avoid neovascular glaucoma and surgical repair of a rhegmatogenous detachment [21]. Therefore, even when functional outcome is limited, performing vitrectomy is justified.

Based on our findings, large-scale studies are on the way to further assess the effect of pars plana vitrectomy with long-term silicone oil tamponade and photocoagulation of the tumor surface in patients ineligible for larger surgical interventions such as endoresection.

\section{References}

$>1$ Kivelä T, Eskelin S, Mäkitie T, Summanen P: Exudative retinal detachment from malignant uveal melanoma: predictors and prognostic significance. Invest Ophthalmol Vis Sci 2001;42:2085-2093.

-2 Coleman K, Baak JP, Van Diest P, Mullaney J, Farrell M, Fenton M: Prognostic factors following enucleation of 111 uveal melanomas. Br J Ophthalmol 1993;77:688-692.

-3 Egan KM, Gragoudas ES, Seddon JM, Glynn RJ, Munzenreider JE, Goitein M, Verhey L, Urie M, Koehler A: The risk of enucleation after proton beam irradiation of uveal melanoma. Ophthalmology 1989;96:13771382; discussion 1382-1383.

-4 Foss AE, Whelehan I, Hungerford JL, Anderson DF, Errington RD, Kasperek A, Restori M, Kongerud J, Sheen M: Predictive factors for the development of rubeosis following proton beam radiotherapy for uveal melanoma. Br J Ophthalmol 1997;81:748-754.

5 Cook B, Lewis GP, Fisher SK, Adler R: Apoptotic photoreceptor degeneration in experimental retinal detachment. Invest Ophthalmol Vis Sci 1995;36:990-996.

6 Chang CJ, Lai WW, Edward DP, Tso MO: Apoptotic photoreceptor cell death after traumatic retinal detachment in humans. Arch Ophthalmol 1995;113:880-886.

7 Berglin L, Algvere PV, Seregard S: Photoreceptor decay over time and apoptosis in experimental retinal detachment. Graefes Arch Clin Exp Ophthalmol 1997;235:306-312.

8 Erickson PA, Fisher SK, Anderson DH, Stern WH, Borgula GA: Retinal detachment in the cat: the outer nuclear and outer plexiform layers. Invest Ophthalmol Vis Sci 1983;24:927-942.

-9 Zacks DN, Hanninen V, Pantcheva M, Ezra E, Grosskreutz C, Miller JW: Caspase activation in an experimental model of retinal detachment. Invest Ophthalmol Vis Sci 2003;44:1262-1267.

$\checkmark 10$ Zografos L, Mirimaoff RO, Angeletti CA, Frosini R, Beati D, Schalenbourg A, Chamot L: Systemic melanoma metastatic to the retina and vitreous. Ophthalmologica 2004;218:424-433.

-11 Conway RM, Poothullil AM, Daftari IK, Weinberg V, Chung JE, O’Brien JM: Estimates of ocular and visual retention following treatment of extra-large uveal melanomas by proton beam radiotherapy. Arch Ophthalmol 2006;124:838-843.

-12 Munzenrider JE, Gragoudas ES, Seddon JM, Sisterson J, McNulty P, Birnbaum S, Johnson K, Austin-Seymour M, Slater J, Goitein MM: Conservative treatment of uveal melanoma: probability of eye retention after proton treatment. Int J Radiat Oncol Biol Phys 1988;15:553-558.

-13 Gragoudas ES, Seddon JM, Egan K, Glynn R, Munzenrider J, Austin-Seymour M, Goitein M, Verhey L, Urie M, Koehler A: Long-term results of proton beam irradiated uveal melanomas. Ophthalmology 1987;94:349-353.

14 Duke-Elder S, Dobree JH: Detachment and folding of the retina; in Duke-Elder S (ed): System of Ophthalmology. Diseases of the Retina. St. Louis, Mosby, 1967, vol 10, pp 775-776.

15 Gibran SG, Kapoor KG: Management of exudative retinal detachment in choroidal melanoma. Clin Experiment Ophthalmol 2009;37:654-659.

16 Parrozzani R, Pilotto E, Dario A, Miglionico G, Midena E: Intravitreal triamcinolone vs intravitreal bevacizumab in the treatment of exudative retinal detachment secondary to posterior uveal melanoma. Am J Ophthalmol 2013;155:127-133.

17 Bach M, Kommerell G: Sehschärfenbestimmung nach europäischer Norm: wissenschaftliche Grundlagen und Möglichkeiten der automatischen Messung. Klin Monatsbl Augenheilkd 1989;212:190-195, with supplement: column 7 in tab.1 (24.02.2002).

18 Kujala E, Damato B, Coupland SE, Desjardins L, Bechrakis NE, Grange JD, Kivelä T: Staging of ciliary body and choroidal melanomas based on anatomic extent. J Clin Oncol 2013;31:2825-2831.

19 Groenewald C, Konstantinidis L, Damato B: Effects of radiotherapy on uveal melanomas and adjacent tissues. Eye (Lond) 2013;27:163-171.

20 Char DH, Bove R, Phillips TL: Laser and proton radiation to reduce uveal melanoma-associated exudative retinal detachments. Am J Ophthalmol 2003;136:180-182.

21 Tran B-K, Schalenbourg A, Bovey E, Zografos L, Wolfensberger TJ: Role of vitreoretinal surgery in maximizing treatment outcome following complications after proton therapy for uveal melanoma. Retina 2013;33:17771783. 
22 Missotten GS, Notting IC, Schlingemann RO, Zijlmans HJ, Lau C, Eilers PH, Keunen JE, Jager MJ: Vascular endothelial growth factor a in eyes with uveal melanoma. Arch Ophthalmol 2006;124:1428-1434.

23 Courdi A, Caujolle JP, Grange JD, Diallo-Rosier L, Sahel J, Bacin F, Zur C, Gastaud P, Iborra-Brassart N, Hérault J, Chauvel P: Results of proton therapy of uveal melanomas treated in Nice. Int J Radiat Oncol Biol Phys 1999; 45:5-11.

24 Gragoudas ES: Proton beam irradiation of uveal melanomas: the first 30 years - The Weisenfeld Lecture. Invest Ophthalmol Vis Sci 2006;47:4666-4673.

25 Dendale R, Lumbroso-Le Rouic L, Noel G, Feuvret L, Levy C, Delacroix S, Meyer A, Nauraye C, Mazal A, Mammar H, Garcia P, D’Hermies F, Frau E, Plancher C, Asselain B, Schlienger P, Mazeron JJ, Desjardins L: Proton beam radiotherapy for uveal melanoma: results of Curie Institut-Orsay proton therapy center (ICPO). Int J Radiat Oncol Biol Phys 2006;65:780-787.

26 Bechrakis NE, Foerster MH: Neoadjuvant proton beam radiotherapy combined with subsequent endoresection of choroidal melanomas. Int Ophthalmol Clin 2006;46:95-107.

-27 Jager MJ, Desjardins L, Kivelä T, Damato BE: Current Concepts in Uveal Melanoma. Dev Ophthalmol. Basel, Karger, 2012, vol 49, pp 41-57.

-28 Dunavoelgyi R, Zehetmayer M, Simader C, Schmidt-Erfurth U: Rapid improvement of radiation-induced neovascular glaucoma and exudative retinal detachment after a single intravitreal ranibizumab injection. Clin Experiment Ophthalmol 2007;35:878-880. 